Aspirasi: Jurnal Masalah-Masalah Sosial | Volume 9, No, 2 Desember 2018

ISSN: 2086-6305 (print) ISSN: 2614-5863 (electronic)

DOI: https://doi.org/10.22212/aspirasi.v7il.1084

link online: http://jurnal.dpr.go.id/index.php/aspirasi/index

\title{
RIDWAN KAMIL: SANG PENDOBRAK STATUS QUO
}

\section{Ridwan Kamil: The Status Quo Breaker}

\author{
Lukman Nul Hakim \\ lukman.nulhakim@dpr.go.id \\ Pusat Penelitian Badan Keahlian DPR RI \\ Jl. Gatot Subroto Senayan Jakarta
}

Naskah Diterima: 2 Oktober 2018 | Naskah direvisi: 5 Desember 2018 | Naskah diterbitkan: 31 Desember 2018

\begin{abstract}
Unlike the 2014 and 2019 presidential elections which brought Joko Widodo vs. Prabowo Subianto together, according to Professor Kacung Marijan, Ph.D., in 2024 presidential election there will be extensive 'menus' that can be offered to the public. Some new candidates are predicted to enliven the 2024 presidential election, including DKI Jakarta Governor Anies Baswedan, Central Java Governor Ganjar Pranowo, and East Java Governor Khofifah Indar Parawansa. The writer added two more people on the list, namely Former DKI Jakarta Vice Governor Sandiaga Uno, and West Java Governor Ridwan Kamil. Preliminary knowledge of the psychological profile of the leaders is important as a basis for selecting future leaders for the people of Indonesia. In this study the writer tried to analyze the profile of one of the potential future leader of Indonesia, Ridwan Kamil $(n=1)$. At-a-distance measurement method is used to do biography analysis and big five analysis. This study concluded that Ridwan Kamil was a person with a high score on the dimensions of openness to experience and extroversion, was middle on conscientiousness, and was low on agreeableness and neuroticism. He doesn't like the status quo. He likes to challenge the limit, both the limit of himself and his environment. The right words to describe Ridwan Kamil is a status quo breaker.
\end{abstract}

Keywords: Ridwan Kamil, personality, big five, at-a-distance method, Indonesian politician

\begin{abstract}
Abstrak: Tidak seperti pemilihan presiden (pilpres) tahun 2014 dan 2019 yang mempertemukan Joko Widodo vs. Prabowo Subianto, menurut Profesor Kacung Marijan, Ph.D., pada pilpres tahun 2024 nanti banyak 'menu' yang bisa disajikan untuk masyarakat. Beberapa kandidat baru diprediksi akan meramaikan pilpres 2024, di antaranya Gubernur DKI Jakarta Anies Baswedan, Gubernur Jawa Tengah Ganjar Pranowo, dan Gubernur Jawa Timur Khofifah Indar Parawansa. Penulis menambahkan dua orang dalam daftar tersebut, yaitu Mantan Wakil Gubernur DKI Jakarta Sandiaga Uno dan Gubernur Jawa Barat Ridwan Kamil. Pengetahuan awal tentang profil psikologis para tokoh tersebut menjadi penting sebagai dasar untuk memilih calon pemimpin masa depan bagi masyarakat Indonesia. Pada penelitian ini, penulis berusaha menganalisis profil salah satu tokoh potensial masa depan Indonesia, yaitu Ridwan Kamil $(n=1)$. Metode pengukuran at-a-distance, digunakan untuk melakukan analisis biografi dan analisis big five. Penelitian ini menyimpulkan bahwa Ridwan Kamil adalah seorang dengan skor yang tinggi pada dimensi openness to experience dan extroversion, menengah pada conscientiousness, dan rendah pada agreeableness dan neuroticism. Ia tidak menyukai status quo. Ia suka menantang ambang batas, baik itu ambang batas dirinya maupun lingkungannya. Kata yang tepat untuk menggambarkan Ridwan Kamil adalah seorang pendobrak status quo.
\end{abstract}

Kata kunci: Ridwan Kamil, kepribadian, big five, metode at-a-distance, politisi Indonesia 


\section{Pendahuluan}

Munculnya Ridwan Kamil dalam kancah perpolitikan nasional merupakan sebuah fenomena yang menarik. Ridwan Kamil bersama dengan Joko Widodo (Jokowi), Tri Rismaharini, Nurdin Abdullah merupakan produk sistem pemilihan kepala daerah (pilkada) secara langsung yang baru berumur 13 tahun. Wacana agar pilkada tidak lagi dilakukan secara langsung melainkan melalui DPRD sempat muncul. Namun demikian ketika pada Kamis 2 Oktober 2014 Presiden Republik Indonesia saat itu yaitu Bapak Susilo Bambang Yudhoyono (SBY) menandatangani Peraturan Pemerintah Pengganti Undang-Undang Nomor 1 Tahun 2014 tentang Pemilihan Gubernur, Bupati, dan Wali Kota (Perppu Pilkada), maka pilkada tetap diselenggarakan secara langsung (Wedhaswary, 2014). ${ }^{1}$ Dengan demikian kemunculan tokohtokoh politik nasional yang meniti karir dari menjadi pemimpin di daerah akan terus berlanjut. Terlepas pro dan kontra terhadap pilkada langsung, menurut Pakar Hukum Tata Negara Refly Harun, pilkada langsung menghasilkan pemimpin yang out of the box (Prabowo, 2014). ${ }^{2}$

Profesor Kacung Marijan, Ph.D (2018) memprediksi bahwa pada pemilihan presiden tahun 2024 nanti akan banyak menampilkan 'menu' yang bisa disajikan untuk masyarakat Indonesia, diantaranya Gubernur DKI Jakarta Anies Baswedan, Gubernur Jawa Tengah Ganjar Pranowo, dan Gubernur Jawa Timur Khofifah Indar Parawansa. Sementara Wall Street Journal edisi 9 Oktober 2013 dengan judul artikel In Indonesia, a New Breed of Politician is on the Rise menuliskan nama-nama yang ke depan diprediksi akan bersinar dan mengisi dunia perpolitikan negeri ini, antara lain Joko Widodo, Ridwan Kamil, Tri Rismaharini dan Anies Baswedan (Otto \& Ismar, 2013). ${ }^{3}$ Untuk

Ini Isi Perppu Pilkada yang Dikeluarkan Presiden SBY, https://nasional.kompas. com /read/2014/ 10/ 03/09190651/ Ini.Isi.Perppu. Pilkada.yang. Dikeluarkan.Presiden.SBY, diakses 27 Februari 2018.

2 Pilkada Langsung Lahirkan Pemimpin yang Out of the Box, http://nasional.kompas. com/read/ 2014/09/11/18441011/ Pilkada.Langsung. Lahir kan.Pemimpin.yang.Out.of.The. Box, diakses 26 Februari 2018.

In Indonesia, a New Breed of Politician Is on the Rise, http://www.wsj.com/ articles /SB1000 1424052 penelitian ini penulis akan memfokuskan diri pada Ridwan Kamil (RK), yang karir politiknya mirip dengan Joko Widodo, yaitu berawal dari menjabat sebagai walikota kemudian promosi menjadi gubernur.

Setelah RK menjabat selama satu periode sebagai Walikota Bandung (2013-2018), ia melanjutkan karir politiknya menjadi Gubernur Jawa Barat periode 2018-2023. Pada tahun terakhir masa baktinya sebagai gubernur nanti, yaitu pada tahun 2023 hanya berjarak satu tahun menjelang pemilihan presiden 2024. Jeda waktu satu tahun ini identik dengan jeda waktu antara ketika RK selesai menjabat sebagai Walikota Bandung dengan waktu pemilihan Gubernur Jawa Barat. Jeda waktu antara tahun 2023-2024 nanti akan memberikan waktu yang cukup bagi RK untuk mempersiapkan langkah selanjutnya yaitu menjadi Gubernur Jawa Barat periode kedua atau maju menjadi wakil presiden atau bahkan presiden Republik Indonesia.

Melihat track record-nya saat menjabat sebagai Walikota Bandung yang dinilai sangat baik berdasarkan survei Laboratorium Quality Control Unpad Bandung (Wiyono, 2016) ${ }^{4}$, jika RK tidak melakukan sebuah blunder politik yang fatal maka diprediksi langkah politik RK sangat prospektif. Ia berpotensi menjadi pemimpin ditingkat nasional.

Mengingat hal-hal tersebut diatas maka pemahaman yang lebih mendalam tentang RK menjadi penting. Karena publik berhak mendapatkan pengetahuan yang lebih mendalam tentang tokoh-tokoh politik negeri ini. Pada artikel ini penulis akan berusaha mempelajari, bagaimanakah profil RK dari perspektif ilmu psikologi? Penulis berusaha mengkaji RK menggunakan teori Big Five, Costa dan McCrae (2003). Hasil penelitian ini diharapkan dapat menambah pengetahuan masyarakat Indonesia akan calon-calon pemimpinnya. Selain itu, artikel ini juga dimaksudkan untuk mengisi kurangnya kajian ilmiah dari perspektif psikologi atas profil tokoh politik nasional.

702303442004579123080039432594 , diakses 1 Maret 2018. Survei Unpad: Warga Bandung Puas terhadap Kinerja Ridwan Kamil, https://www.merdeka. com/peristiwa/ survei-unpad-warga-bandung-puas-terhadap-kinerjaridwan-kamil.html, diakses 27 Februari 2018. 
Peneliti melakukan analisa atas RK berdasarkan 5 aspek teori Big Five Costa dan McCrae (2003) yang menyoroti openness to experience, conscientiousness, extraversion, agreeableness, dan neuroticism. Berdasarkan data tertulis maupun video, peneliti mencari fakta-fakta yang mendukung pengkategorian kepribadian RK berdasarkan kelima aspek. Pada masing-masing aspek terdapat rentang nilai 1 untuk kategori sangat rendah sampai dengan 12 untuk kategori sangat tinggi. Setelah melakukan klasifikasi kemudian dilakukan tabulasi skor untuk kemudian dilakukan analisa.

Penelitian ini menggunakan metode at-adistance, yaitu sebuah metode yang dikembangkan oleh para ilmuwan bidang kebijakan luar negeri untuk melakukan pengukuran psikologis dari jarak jauh (Dille \& Young, 2000). Hasil penelitian dengan metode ini jika dilakukan dengan sistematis dan objektifakan memberikan masukan yang berguna bagi pengambil kebijakan publik (Winter, 1992). Hermann (1984) mengingatkan bahwa hasil penelitian yang menggunakan teknik at-a-distance harus berhati-hati dalam pengambilan materi penelitian baik itu pidato maupun video yang tersedia karena seringkali tokoh menggunakan ghost writer, yaitu orang yang bertugas menyusun materi pidato. Selain itu, tokoh juga tidak menunjukkan bahasa tubuh yang spontan ketika di depan video. Untuk itu, pada penelitian ini penulis hanya menggunakan video dan naskah pidato yang tidak dalam suasana resmi, melainkan pada suasana spontan.

Selain itu pada beberapa bagian penulis juga mengutip tulisan asli RK dari berbagai media sosial seperti twitter dan askfm. Pada kutipan tersebut penulis membiarkan tulisan-tulisan tersebut apa adanya. Sebagai contoh penulis tidak mengubah kata berbahasa Inggris menjadi italic, termasuk juga kesalahan-kesalahan penulisan (typos) yang dilakukan oleh RK.

\section{Biografi Singkat}

Mochamad Ridwan Kamil atau sering dipanggil Kang Emil lahir di Bandung pada hari Senin, 4 Oktober 1971. Ridwan Kamil lahir dari sepasang pendidik. Ayahanda Ridwan Kamil
(RK) adalah seorang dosen di Fakultas Hukum Universitas Padjadjaran (UNPAD), sedangkan Ibunda RK adalah dosen jurusan Farmasi di Universitas Islam Bandung (UNISBA).

RK beristrikan Atalia Praratya yang masih keturunan pendiri Kota Bandung, Raden Haji Abdullah yang pada masanya seorang Hoofd (Kepala) Penghulu Bupati Bandung (Prasetyo, 2014). ${ }^{5}$ Atalia kelahiran 20 November 1973, dan tercatat mengikuti pendidikan $\mathrm{S} 1$ jurusan Hubungan Internasional di Universitas Parahyangan. Ia juga mengikuti program diploma bidang ekonomi di Universitas Padjajaran. RK dan Atalia mempunyai dua orang anak, seorang anak laki-laki yang lahir di New York pada tanggal 25 Juni 1999, dan seorang anak perempuan yang lahir pada tanggal 17 Agustus 2004.

RK anak ke dua dari 5 bersaudara. Rentang usia RK dan kakak pertamanya sekitar 7 tahun. Kakakpertama RKlulusan Jurusan Astronomi ITB angkatan tahun 1988. Sang Kakak sempat meniti karir dibidang Human Resource Management di sebuah Bank milik negara, sejak lulus S1 sampai kemudian pindah ke perusahaan retail dengan jabatan terakhir ketika tulisan ini dibuat adalah sebagai General Manager. Adik RK yang juga merupakan saudara perempuan satu-satunya menyelesaikan pendidikan S1 psikologi dan S2 profesi psikologi di Universitas Padjadjaran. Saat ini, ia berprofesi sebagai dosen. Selanjutnya anak ke-4 adalah lulusan Fakultas Ekonomi Universitas Padjadjaran dan melanjutkan studi S2 di Australia. Terakhir masih ada adik laki-laki RK yang paling bungsu.

Setelah menamatkan Sekolah Dasar di SDN Banjarsari III Bandung pada periode 19781984, RK melanjutkan pendidikan di sekolahsekolah favorit di Kota Bandung, yaitu SMP Negeri 2 Bandung (1984-1987) dan SMA Negeri 3 Bandung (1987-1990). Kemudian RK melanjutkan studi tingkat perguruan tinggi di Institut Teknologi Bandung (1990-1995). Setahun setelah lulus kuliah, pada 7 Desember 1996 RK menikahi Atalia Praratya. Setahun kemudian RK memutuskan memboyong istri

Istri Walikota Masih Keturunan dalem Bandung, http:// www.tribunnews.com/regional/ 2013/09/24/istri-wali-kotamasih-keturunan-dalem-bandung, diakses 26 Februari 2018. 
pindah ke Amerika Serikat untuk bekerja di firma arsitek. Dua tahun RK bekerja di Amerika Serikat, selanjutnya ia juga sempat bekerja di Hongkong selama dua tahun. Setelah empat tahun bekerja, RK memutuskan melanjutkan pendidikan tingkat master di University of California Berkeley dengan peminatan Urban Design (1999-2001).

\section{Analisis Biografi}

Menjadi anak nomor 2 dari 5 bersaudara dan tidak memiliki kemiripan nama dengan saudara-saudara laki-lakinya yang mempunyai unsur nama "Zaman", yaitu Muniruzaman, Nazmuzzaman, dan Komaruzaman, membuat RK merasa berbeda dari saudara-saudaranya. Ia juga merasa kurang diperhatikan oleh orang tuanya, terutama ayahnya (Herlambang, 2009). ${ }^{6}$ Emosi kekecewaan dan perasaan menjadi korban ketidakadilan itu di satu sisi diekspresikan dengan sering berbuat nakal, berkelahi, memberontak dan tidak patuh (low on dutifulness) terhadap ayahnya. Bahkan muncul keinginan untuk bisa melampaui ayahnya. Sementara di sisi lain, kondisi itu justru memberikan energi untuk menonjol dengan berprestasi, sehingga hasrat untuk mencapai prestasi (achievement striving) yang tinggi pada RK tumbuh, berkembang dan telah membentuk kepribadiannya.

Merujuk pada Family Constellation Adler, terdapat indikasi khas anak kedua pada RK, yaitu kompetitif, ada kecenderungan ingin mengalahkan kakaknya, dan berperilaku memberontak. Di saat bersamaan, juga terdapat indikasi khas anak tengah, yaitu menjadi pejuang ketidakadilan. Sebagai seorang pejuang keadilan, RK bahkan berani mempertanyakan kebijakan ayahnya, satu hal yang tabu dilakukan pada budaya Sunda yang sangat menghormati orang tua.

Kakak RK seorang yang menonjol. Sang kakak secara fisik menarik dan ia juga pintar. Ia kuliah jurusan Astronomi di ITB, sempat menjadi pengajar di sebuah bimbingan belajar dengan RK salah satu peserta didiknya, dan saat ini sukses dengan karirnya sebagai General Manager disebuah perusahaan retail. Menjadi

Ridwan Kamil, http://rustikaherlambang.com /2009/04/29/ ridwan-kamil, diakses 27 Februari 2018. adik dari kakak yang menonjol tentunya menjadi tantangan tersendiri bagi seorang RK, dan hal ini berpotensi menjadi salah satu faktor yang mendorongnya untuk lebih baik.

Dalam bukunya yang berjudul Mengubah Dunia Bareng-bareng, RK mengakui perbuatanperbuatan nakal yang pernah dilakukannya. Pada halaman kedua ia menuliskan bahwa sewaktu kecil ia suka menjahili temannya, mengintip anak perempuan, kabur tidak membayar angkot, mencabut tanaman genjer milik orang lain, bermain bola dalam kelas sehingga tanpa sengaja membuat kaca kelas pecah. Untuk kasus terakhir bahkan mengakibatkan ia dan temannya menerima konsekuensi membersihkan toilet sekolah selama seminggu. Tidak heran jika pada kolom catatan guru di buku rapor tertulis "anak ibu berprestasi tetapi nakal'. Kemudian catur wulan selanjutnya tertulis "pintar tetapi nakal" dan lain waktu tertulis "harus lebih diawasi supaya tidak nakal". Dengan demikian, pintar dan nakal menjadi label yang melekat pada RK baik pada benak orangorang maupun dirinya sendiri.

Sewaktu RK kecil, ayahnya mempunyai kebiasaan menayangkan foto-foto yang diabadikan dari hasil kunjungannya ke luar negeri. Foto-foto kota dengan latar belakang pemandangan arsitektur yang berbeda dari Kota Bandung membuat RK sangat tertarik. Tanpa disadari slide demi slide foto itu berpengaruh besar bagi RK karena foto-foto itu memberikan RK kecil suatu khayalan (fantasy). RK kerap membayangkan dirinya yang berada di situ bersama tokoh-tokoh superhero yang ia sering baca di komik-komik kesayangannya. Aktivitas berfantasi, menyaksikan dan menikmati keindahan (aesthetics) kota-kota di luar negeri itu di kemudian hari menjadi keunggulan RK dalam ide-ide (ideas) desain-desain arsitekturnya sehingga menjadi modal ketika studi, bekerja untuk firma arsitek, dan perusahaan Urbane yang ia dirikan. Bahkan fotografi kemudian menjadi salah satu hobinya.

Rendahnyakepatuhan(lowondutifulness) RK atas peraturan ataupun kebiasaan di lingkungan keluarganya tidak berhenti di masa kanakkanak. Semasa sekolah menengah atas, ia pernah 
dicambuk oleh ayahnya menggunakan selang air karena mengoleksi gagang telepon umum yang telah ia ambil dan dipajang di kamarnya. Di lain waktu, RK juga melakukan hal yang tidak 'biasa' lainnya yaitu mempertanyakan kebijakan orang tua, yang dalam budaya Sunda pada saat itu dianggap tabu. Kejadiannya yaitu pada saat makan bersama keluarga, RK menganggap lauk yang ia dan saudara-saudaranya makan berbeda dengan ayahnya. Pada saat itulah, sikap asertif RK muncul. RK mempertanyakan kebijakan pembagian makanan yang menurutnya tidak adil itu ke ayahnya. Sikap asertif yang ditunjukkan RK sulit muncul pada orang yang tidak kritis dan tidak mempunyai keberanian untuk mendobrak kebiasaan pada saat itu. Sikap kritis RK muncul dari kecerdasannya. Sementara keberaniannya muncul dari berbagai pengalaman dalam melanggar ambang batas rasa takut yang pernah ia lakukan sebelumnya.

Salah satu fase penting dalam kehidupan seseorang adalah ketika memutuskan jurusan kuliah setelah lulus SMA. Begitu juga dengan RK. Berdasarkan liputan wawancara Pramantie $(2014)^{7}$ di Tabloid Nova, RK menceritakan bahwa sesungguhnya pilihan utamanya saat itu adalah teknik kimia. Pilihan tersebut berdasarkan saran dari temannya, yang memang saat itu kuliah di jurusan teknik kimia. Sementara itu, pilihan keduanya adalah arsitektur dengan alasan banyak teman-temannya yang mengambil jurusan ini. Melihat proses pengambilan keputusannya saat itu, terlihat besarnya peran orang-orang disekitarnya. Pada proses ini terlihat karakteristik kesukaannya berkumpul dan berdekatan dengan teman-temannya (gregariousness) dan mencari kesenangan (excitement seeking) yang merupakan facet dari kepribadian ekstrovert. Disaat yang bersamaan, RK juga menunjukkan sumber motivasinya berasal dari luar diri (eksternal).

Namun demikian, ketika memasuki perkuliahan, RK merasa telah salah memilih jurusan sehingga sempat patah semangat. Beruntung ia memiliki ayah yang peduli dan menyemangatinya (sumber motivasi eksternal),

Ridwan Kamil Laki-Laki Penuh Imajinasi, http://www. tabloidnova.com/Nova/Profil/Ridwan-Kamil-Laki-LakiPenuh-Imajinasi-1/, diakses 27 Februari 2018. sehingga ia kembali menemukan passion-nya di bidang arsitektur. Selain itu ia juga aktif berorganisasi. Berkat keaktifannya (activity level) di himpunan jurusan, pada tahun 1994 ia terpilih dalam pertukaran pelajar mewakili ITB dan menetap selama 6 bulan di Singapura.

Selanjutnya pada masa akhir perkuliahan S-1 yaitu tahun 1995, RK mengalami salah satu periode paling sulit dalam hidupnya. Di saat ia sedang menyelesaikan tugas akhir, pacar yang merupakan cinta pertamanya meninggalkannya untuk memilih pria yang lebih mapan. Sementara pada saat itu sang ayah sedang terkena penyakit yang menyerang serum darah sehingga harus dirawat di ICU. RK menceritakan bahwa saat itu ia terus berusaha menyelesaikan tugas akhir meski sulit fokus. RK terus menyemangati diri dengan mengatakan pada diri sendiri "Saya bisa! Saya pasti bisa!" Akhirnya, RK mampu menyelesaikan tugas akhirnya dengan membuat 24 lembar dari hanya 16 lembar yang ditugaskan, sehingga mendapat nilai A++. RK lulus dengan IPK 2.77 (Kamil dkk, 2015: 9). Dari kejadian ini terlihat bahwa ia mempunyai determinasi dan hasrat berprestasi (achievement striving) yang tinggi dengan berhasil menemukan sumber motivasi dari dalam diri, bukan dari luar seperti yang biasanya didapatkan.

Pada usia 25 tahun (tahun 1996) RK memutuskan menikahi Atalia Praratya yang menurutnya memenuhi kriteria wanitaidamannya, yaitu memiliki wawasan yang luas, pandai berkomunikasi, bisa berbahasa Sunda, dan seksi seperti seniman film Aura Kasih (Herlambang, 2009). RK yang pada saat itu masih muda dan belum mapan memberanikan diri untuk menikahi Atalia karena merasa menemukan sosok yang tepat untuk menjadi istrinya. Selain itu, RK mempunyai banyak saingan yang pada saat yang sama juga sedang mendekati Atalia.

Setahun setelah menikah (tahun 1997), RK memutuskan untuk mendobrak kondisi dirinya saat itu dengan bekerja di Amerika Serikat (AS). Namun, baru empat bulan bekerja, perusahaan memutuskan hubungan kerja karena krisis moneter pada saat itu. Padahal, saat itu istrinya sedang hamil tua. RK dihadapkan pada pilihan 
kembali ke tanah air dengan konsekuensi rasa malu karena baru empat bulan lalu ia meninggalkan Indonesia dengan memberi impian kesuksesan bagi keluarganya atau menetap di AS dengan risiko kesulitan hidup. RK memilih opsi kedua. Selama kurun waktu 7 tahun di luar negeri, RK juga sempat tinggal dan bekerja di Hongkong selama dua tahun dan melanjutkan kuliah S-2 jurusan Urban Design di University of California (1999-2001).

Tahun 2004, RK kembali ke Indonesia dan mendirikan Perusahaan Urban Evolution atau Urbane. RK aktif dalam kegiatan sosial Bandung City Creative Forum, membentuk Indonesia Berkebun, menginisiasi bike.bdg, dan menciptakan enerbike. Selanjutnya, dengan modal sosial yang tinggi, RK mencalonkan diri menjadi Walikota Bandung dengan dukungan Partai PKS dan Gerindra dengan tanpa menjadi anggota dari kedua partai itu.

\section{Analisis Kepribadian Menggunakan Big Five}

Pada bagian ini penulis menyajikan analisis kepribadian RK menggunakan alat ukur kepribadian Big Five yang melihat lima dimensi, yaitu openness to experience, conscientiousness, extraversion, agreeableness dan neuroticism.

\section{Openness to Experience: Tinggi pada Facet Fantasi, Aesthetics, Ideas, Actions dan Value (Skor 12)}

Salah satu karakteristik yang paling menonjol pada diri RK adalah pada faktor openness to experience (O). Openness to experience umumnya untuk menggambarkan orang yang terbuka, senang mendapatkan pengalaman baru, dan memandang pengalaman sebagai sumber kehidupan. Openness to experience terdiri dari enam facet yaitu fantasy, aesthetics, feelings, ideas, actions, dan value. RK mendapatkan penilaian yang sangat tinggi untuk penilaian pada faktor ini karena dari keenam facet pada faktor $\mathrm{O}$, hampir semua facet konsisten muncul pada perilaku RK.

RK adalah seorang pengkhayal. Pada banyak kesempatan, RK memang mengatakan bahwa hobinya adalah berkhayal (TEDxTalks, 2010; Pramantie, 2014). Aktivitas berkhayal (fantasy)
RK telah dipupuk, disadari atau tidak, oleh sang ayah sejak masih kecil, melalui tayangan fotofoto di luar negeri (Herlambang, 2009). Semasa kuliah, hobinya semakin terfasilitasi karenabidang studi arsitektur ditekuninya, mendorongnya untuk terus berkhayal. Khayalannya kemudian dituangkan dalam gambar desain bangunan yang harus melalui perhitungan matematis yang sangat matang. Dari sini, otak kanan dan kirinya bukan hanya dipaksa berfungsi, tetapi juga bekerja sama. Aktivitas berkhayal itu berlanjut sampai dunia kerja. Dengan memilih menjadi seorang arsitek profesional, maka berkhayal tidak hanya menjadi hobi melainkan telah menjadi tuntutan pekerjaan. Saat menjabat sebagai Walikota Bandung, kreasi khayalannya berlanjut dengan pembangunan banyak taman, seperti Taman Superhero, Taman Jomblo (Pasopati), Taman Persib, Taman Lansia, dan lain-lain. RK juga mengimplementasikan khayalannya agar Bandung mempunyai banyak CCTV layaknya kota-kota modern di dunia, dengan pusat pengendalian yang disebut command centre. Atas pertimbangan hal-hal di atas maka RK mendapatkan penilaian yang tinggi pada facet fantasi atau khayalan ini.

Sementara dari facet keindahan (aesthetic), maka berbagai prestasinya dalam bidang desain arsitektur menjadi fakta yang sahih akan karakteristik aesthetic pada diri RK. RK bersama perusahaan yang dipimpinnya (Urbane), telah memenangkan 20 penghargaan dalam bidang arsitektur (Utari, 2015). ${ }^{8}$ Ia pernah dinobatkan sebagai Young Design Entrepreneur of The Year dari British Council (tahun 2006), predikat Architect of The Year oleh Elle Decor Magazine (tahun 2009), Top Ten Architecture Business Award dari BCI Indonesia (tahun 2009), Top Ten Architecture Business Award dari BCI Indonesia (tahun 2008); Winner of International Design Competition for Aceh Tsunami Museum (tahun 2007); Winner of International Design Competition - Waterfront Retail Masterplan, Suzhou, RRC (tahun 2005); Winner of International Design Competition - Kunming Tech Park, Kunming, RRC (tahun 2005); dan

Ridwan Kamil Obsesi Evolusi Membawa Prestasi, https:// attalicious.Word press.com /2010/02 /15/ridwan-kamilobsesi-evolusi-membawa-prestasi/, diakses 1 Maret 2018. 
Winner of International Design competition Islamic Center, Beijing, RRC (tahun 2004). Masjid Al Irsyad hasil desain RK di Kota Baru Parahyangan dinobatkan sebagai satu dari 25 masjid terindah versi Complex Magazine. Setelah menjabat sebagai walikota, kesukaan RK dengan keindahan masih terus berlanjut. Pada tanggal 31 Desember 2014 RK meresmikan taman alun-alun Bandung yang mendapat apresiasi positif dari masyarakat Bandung (Gumilar, 2014). ${ }^{9}$

RK tipikal orang yang terbuka pada ide-ide (ideas) baru. Ia menghargai pengetahuan. Hal ini tercermin dari pernyataannya dalam program wawancara Kompas TV “Aiman dan RK” bahwa ia telah menjadikan hasil kunjungannya kurang lebih ke 120 kota di dunia sebagai sumber referensinya untuk menata Kota Bandung (Kamil $\mathrm{dkk}, 2015)$.

Dalam membangun Kota Bandung, RK juga membangun jalur komunikasi yang cepat, langsung, dan tanpa perantara dengan seluruh masyarakat melalui berbagai media sosial seperti twitter, instagram, facebook, ask.fm. Penggunaan media sosial untuk mengelola sebuah kota merupakan sebuah terobosan yang berani dan baru di Indonesia. Penggunaan media sosial untuk kegiatan sosial kemasyarakatan bahkan telah dilakukannya sebelum menjadi walikota seperti menginisiasi komunitas bandung berkebun melalui perantaraan media sosial sehingga menular ke beberapa wilayah di Indonesia. Dari kegiatan tersebut muncul diantaranya kelompok Indonesia berkebun, Bekasi berkebun, dan Depok berkebun.

Keterbukaannya akan ide baru juga ditunjukkan dalam mengantisipasi kriminalitas di Kota Bandung. RK menginisiasi digunakannya aplikasi panic button, sebuah aplikasi berbasis android yang bisa di download di handphone dan terkoneksi dengan kepolisian, sehingga jika seseorang menjadi korban kriminalitas bisa langsung memencet tombol tersebut di HP mereka yang kemudian akan ditindaklanjuti kepolisian. Ketika ditanya Aiman dalam

\footnotetext{
Hore Taman Alun-Alun Bandung sudah Diresmikan. http:// news.metrotvnews.com/read /2014/12/31/339017/horetaman-alun-alun-bandung-sudah-diresmikan, diakses 2 Maret 2018.
}

wawancara Kompas TV dari mana ide itu berasal, RK mengatakan "ide itu memang sudah ada, di google aja” (Kompas TV News, 2014). Jawaban itu menunjukkan terbukanya RK atas ide-ide dari manapun asalnya.

RK juga menunjukkan sense of curiosity yang tinggi, setidaknya pada hal-hal yang menjadi minatnya seperti keikutsertaannya di berbagai media sosial. Setelah aktif bergabung facebook, twitter, dan instagram, RK kemudian mencoba media sosial baru pada bulan Agustus 2014 atau setelah menjabat sebagai walikota, yaitu askfm, sebuah media sosial yang memperbolehkan siapa saja menanyakan apa saja kepada siapa saja yang menjadi sesama pengguna ask.fm.

Ada tipe orang yang sangat menikmati comfort zone sehingga ketika memesan makanan di sebuah restoran, cenderung memesan masakan yang sama atau menghabiskan hidupnya dari kecil hingga dewasa di tempat dan lingkungan yang sama. Tetapi kebalikan dengan RK. Ia tipe orang yang berani mencoba sesuatu yang baru. Ia berani mengambil tindakan yang baru dan meninggalkan comfort zone. Misalnya, RK berani berangkat ke AS untuk bekerja dengan membawa istrinya, kemudian tinggal di Hongkong selama 2 tahun, dan menjelajah lebih dari 120 kota di dunia. Fakta-fakta itu merupakan cerminan seseorang dengan karakter openness to experience khususnya pada facet tindakan (action) yang tinggi.

Dalam hal nilai-nilai (value), RK lebih mengedepankan nilai-nilai intelektual dibandingkan nilai-nilai konservatif. Sebagai contoh, pernyataannya tentang nilai yang dianut terkait dunia desain arsitektur. Saat memberikan presentasi di TEDx Jakarta, RK mengatakan bahwa "...katanya di Jawa Tengah (desain) harus joglo, saya bilang itu kan warisan arsitek pada zaman dahulu kala, masa harus ditiru sampai kiamat, kan enggak, saya generasi saya, tapi tetep menghormati nilai-nilai gitu, jadi bukan fisiknya yang dicontek, tapi tradisinya, value-nya yang kita teruskan". (TEDx Talks, 2010).

Contoh lain pada acara Mata Najwa (Najwa, 2014). Najwa Shihab saat itu mengatakan bahwa ia mempunyai kesan RK sebagai walikota yang 
didukung PKS maka kebijakan RK mengikuti ideologi PKS. Najwa Shihab mengatakan “... arahnya sudah agak jelas nih karena kemudian ada jam malam yang diperketat...”. Ridwan Kamil menjawab “...jam malam itu tidak ada hubungan (dengan ideologi), karena itu polisi, polisi merekomendasi yang harusnya jam 3 tutupnya jam 12, faktornya karena faktor pure keamanan menurut versi polisi "..kan masa saya tidak percaya sama polisi.." katanya. Kebijakan yang dikeluarkan Ridwan Kamil memang mengandung nilai konservatif, bahwa hiburan malam tutup lebih awal, akan tetapi ia menggunakan alasan dengan pendekatan intelektual.

RK sangat menunjukkan perasaan (feeling) nya terhadap Bandung. Berbagai pengalaman yang didapat dari hasil kunjungan ke 120 kota, ia gunakan untuk memperbaiki Kota Bandung seperti tulisan di bukunya "Bagi saya, Bandung bukan hanya nama kota, ia juga merupakan filosofi hidup (Kamil \& Abdurrahim, 2014)." Ekspresi perasaannya kepada kota kelahirannya juga diekspresikan melalui kata-kata di twitter berikut ini:

“@ridwankamil 21 November 2010: Capek. Tapi cinta. Itu perasaan saya dengan Bandung.

@ridwankamil 24 Januari 2014: Bandung is not a place. It's a feeling" Have a good rest everyone."

\section{Conscientiousness: Rendah pada Facet Dutifulness, dan Tinggi pada Facet Achievement Striving dan Competence (Skor 7)}

Conscientiousness dinilai dari keenam facet yang terdiri dari: self discipline, dutifulness, competence, order, deliberation, dan achievement striving. RK menonjol pada facet achievement striving dan competence, dan sebaliknya rendah pada dutifulness.

Rendahnya penilaian pada facet kepatuhan (dutifulness) karena terdapat beberapa jejak peristiwa yang menunjukkan hal ini dari seorang RK. Seperti kenakalan yang pernah dilakukan saat kanak-kanak maupun remaja sebagaimana telah dijelaskan sebelumnya. RK juga pernah melakukan pelanggaran hukum saat di Amerika
Serikat. Dalam bukunya yang berjudul Mengubah Dunia Bareng-bareng RK menuliskan:

"Malam hari, saat semua karyawan sudah pulang, saya mengendap-endap masuk ke ruangan bos, mengambil selembar cek kosong yang biasa digunakan untuk menulis gaji. Sengaja saya ambil lembar terbawah supaya kalau ketahuan bos, mungkin saat itu saya sudah tidak ada di kantor ini”. (Kamil, AmaLee, Rahman, \& Shafiyah, 2015).

Tindakan itu dilakukan RK agar bisa menuliskan jumlah gaji yang lebih kecil dari sebenarnya agar masuk kategori miskin, sehingga istrinya bisa melahirkan dengan gratis.

Fakta yang menunjukkan perilaku rendah dalam facet dutifulness lainnya adalah keputusan RK untuk mencalonkan diri sebagai Gubernur Jawa Barat dengan tidak melalui partai yang mendukungnya saat menjadi Walikota Bandung.

Contoh fakta lain adalah ketika RK masih menjabat walikota, saat itu sedang ramai wacana Pilkada melalui DPRD. Partai terbelah menjadi dua kubu, yaitu kubu Koalisi Merah Putih (KMP) yang terdiri dari dua partai pendukung RK (PKS dan Gerindra). Kubu ini mendukung pilkada melalui DPRD. Sementara kubu lain, yaitu Koalisi Indonesia Hebat menginginkan pilkada langsung. Menanggapi hal tersebut, RK menyatakan melalui akun twitternya@ ridwankamil, Kamis 11 September 2014 sebagai berikut:

"Secara resmi saya menyatakan
MENDUKUNG pilkada langsung ol rakyat.
UUD 1945 nyatakan "kedaulatan ada di
tangan rakyat."

Selanjutnya untuk facet kompetensi (competence) berbagai penghargaan baik ketika masih menjadi arsitek, pengusaha ataupun walikota, cukup menggambarkan bahwa RK memiliki kompetensi pada dua profesi yang ditekuninya. Sebagai arsitek berbagai capaian telah diraihnya sebagaimana telah dituliskan sebelumnya. Sementara sebagai walikota, RK juga mendapatkan banyak penghargaan seperti Best IT Innovation Mayor untuk pemimpin daerah yang banyak melakukan inovasi untuk memajukan 
daerahnya melalui teknologi informasi dan kota peduli lingkungan, yang sudah diraih dua tahun berturut-turut.

Berbagai achievement yang telah diraih RK tersebut menunjukkan tingginya skor RK untuk facet achievement striving. Usaha RK ketika menyelesaikan laporan akhir S-1 di ITB sampai mendapat nilai $\mathrm{A}++$ juga menunjukkan achievement striving RK. Fakta lain yang ikut mengkonfirmasi achievement striving seorang RK adalah keputusannya untuk bekerja di luar negeri dan mengambil S-2 di Amerika Serikat. Ia bahkan menulis di bukunya bahwa ia memang suka menantang diri sendiri. Hal itu mendorongnya untuk membuktikan kemampuannya kepada orang yang meremehkan dan mencemooh kemampuannya (Kamil, AmaLee, Rahman, \& Shafiyah, 2015).

Untuk ketiga facet lainnya, self discipline, order, dan deliberation penulis tidak mendapatkan cukup data untuk dikemukakan, sehingga penulis tidak merasa yakin untuk memberikan penilaian rendah atau tinggi pada ketiga facet tersebut.

\section{Extroversion: Tinggi pada Semua Facet (Skor 12)}

Faktor extraversion terdiri dari: facet gregariousness, warmth, assertiveness, activity level, excitement seeking, dan positive emotion. Pada faktor ini RK mendapatkan penilaian yang tinggi.

Karakter RK yang suka berkumpul (gregariousness) seperti keikutsertaannya dalam komunitas Bandung Creative City Forum, TEDx Jakarta, TEDx Bandung serta inisiatifnya membentuk Indonesia Berkebun dan bike.bdg, telah membuktikan karakter RK. Bahkan sejak kanak-kanak, RK suka mengikuti olahraga jenis kelompok seperti bola. Selain itu, partisipasinya di OSIS sewaktu SMP maupun tim Paskibra sewaktu SMA mendukung hipotesis bahwa RK bukan tipe orang yang memilih hanya berdiam diri tanpa aktivitas sosial. RK lebih suka berkumpul dengan orang-orang.

Facet kehangatan (warmth) terlihat dalam interaksinya dengan orang-orang pada beberapa video yang penulis observasi. Pada acara hitam putih, dengan mudah tanpa canggung, RK menunjukkan kehangatannya dengan ibunya dengan tidur di paha ibunya. Pada episode hitam putih tersebut, Ibu RK bercerita bahwa suatu ketika ia bertemu RK di Taman Lansia. RK kemudian tiduran di paha sang ibu sampai ketiduran di taman tersebut. RK juga sangat bangga dengan kebiasaannya berpelukan 20 detik dengan keluarganya. Kebiasaan keluarga yang menunjukkan kehangatan itu sering disampaikan pada beberapa kesempatan seperti pada acara Ini Talk Show dan Hitam Putih. Fakta kehangatan seorang RK juga terlihat pada video presentasi TEDxTalks (2010) dan video Apel Siaga PKS (PKS TV, 2014). Pada kedua video tanpa teks itu RK di sela-sela bicaranya, menyebutkan nama beberapa orang yang hadir dan mengapresiasi beberapa hal detail dari orang-orang itu. Hal-hal itu menunjukkan karakter RK yang hangat (warmth).

Berdasarkan catatan penulis fakta yang menunjukkan perilaku asertif (assertiveness) RK merujuk pada insiden ketika ia berani mempertanyakan kebijakan pembagian makanan ke ayahnya. Tindakan asertif juga terlihat ketika RK melakukan sidak ke sebuah cafe di Bandung yang melanggar peraturan. Pada video dengan judul "RK mengamuk" di pusat hiburan Bandung itu, terlihat RK berbicara dengan nada tinggi sambil menunjuk-nunjuk ke pengelola cafe. Perilaku asertif lainnya seperti telah ditulis sebelumnya adalah ketika RK menunjukkan ketidaksetujuannya dengan pilkada melalui DPRD.

Untuk tingkat aktivitas (level of activity) RK kembali mendapatkan skor yang tinggi. Dibukunya (Kamil dkk, 2015) RK menuliskan bahwa energinya berlebih, sehingga membuat dirinya aktif melakukan banyak hal. Semasa SMP, RK aktif di OSIS (Noer, 2015), SMA aktif di Paskibra dan sepak bola (89939893116992b, 2014), ketika kuliah aktif di Himpunan Mahasiswa Jurusan. Sikap aktifnya semasa kuliah S1 di ITB membuat RK mendapat beasiswa studi 6 bulan di Singapura.

Sebelum menjadi walikota, meskipun menjabat sebagai pimpinan Perusahaan Urbane, RK juga menginisiasi kegiatan sosial Indonesia 
berkebun, program bike sharing bike.bdg, dan menciptakan enerbike, sebuah sepeda yang menghasilkan listrik. Pada video wawancara Aiman dan RK (Kompas TV News, 2014), ia menceritakan aktivitasnya:

“...5 bulan ini memang benangnya kusut jadi diurai satu-satu waktu normal nggak cukup jadi tiap hari pulang jam $12 \ldots$ week end juga Undangan warga sangat padat. Iya kalo dulu jaman kampanye abis subuh sekarang sih jam 8 lah jam kerja. Saya kerja dulu mengorganisasikan biasanya sampe tengah hari tengah.. hari ke jam 4 saya banyak di lapangan, dari jam 4 sampe jam 7 malam biasanya nerima warga. Ngelebihin jam dokter... Jam 7 ke malam baru situasional yg sifatnya kalo ada proposal pekerjaan menerima delegasi yang sifatnya besar dst. Biasanya itu minggu siang.... minggu siang.. jadi kalo minggu pagi sampai siang justru banyak banget kegiatan.. kayak besok kalo hari minggu misalkan kita ada launching gerakan kedisiplinan lalu lintas dengan kapolres macam macam... siang ke malam di hari minggu atau sore ke malem kalo betul2 gak bisa itu hari keluarga"

RK termasuk kategori tinggi untuk facet mencari kesenangan (excitement seeking). Menceritakan kisah-kisah lucu hampir selalu mewarnai tayangan video wawancara yang telah penulis observasi (Ini Talk Show di Net TV, Aiman dan RK di Kompas TV, Hitam Putih di Trans7, Apel PKS, dan ceramah bersama Aa Gym). Bahkan ia tampil pada acara stand up komedi Kompas TV. Di acara Ini Talk Show yang dipandu Sule dan Andre Taulani, RK menunjukkan bahasa tubuh yang sangat rileks dan tidak menggambarkan gaya yang berusaha menjaga image dirinya sebagai seorang Walikota. Sebagai contoh pada bagian awal acara, RK langsung menuju sofa dari arah belakang dan duduk dengan menggelosor dari punggung bangku.

RK seringkali menuliskan kalimat motivasi pada akun sosial medianya seperti twitter, facebook ataupun tanya jawab di ask.fm. Berikut beberapa kutipannya:

\section{“@ridwankamil 3 Maret 2013:}

Karena hidup harus optimis. Semangat ya barRT@barasaputra: "Kata demi kata yg dilontarkankang@ridwankamil jadi penyemangat gua".

@ridwankamil 6 Maret 2013:

Mari berlari.Hup RT @mangibam: Bandung Juara Indonesia!! Re Pagi yang cerah. Secercah masa depan kota kita. Krn hidup adl semangat optimis.

@ridwankamil 28 Januari 2011:

Lebih baik nyalakan lilin kecil daripada mengutuki kegelpan. Yuk, optimis!"

\section{Ask.FM 19 Agustus 2014:}

Pak saya kagum dengan bapak di acara kultum supermentor 3 (Rida Demsy). Kemudian dijawab oleh RK: When you work with passion, good things will come.

Status facebook Ridwan Kamil untuk Bandung minggu 28 Maret 2015:
"Selamat pagi warga Bandung tercinta, tema hari ini adalah \#MingguBerbagi. Hayu berbagi kegembiraan bersama keluarga sambil menikmati akhir pekan di taman- taman yang sudah tersedia. Titip jaga fasilitas dan kebersihannya ya. Karena bahagia itu sederhana."

\section{Agreeableness: Secara Umum Rendah (Skor 6)}

Agreeableness adalahkondisiataukualitas diri seseorang yang memiliki perilaku menyenangkan atau ramah dalam bergaul dengan orang-orang lain. Dalam teori Big Five, agreeableness terdiri dari facet straightforwardness, trust, altruism, modesty, tendermindedness, dan compliance.

Untuk menganalisa facet straightforwardness penulis mencatat beberapa pernyataan RK yang tidak konsisten. Seperti terkait kemungkinan ia mencalonkan menjadi presiden di tahun 2019. Melalui ask.fm, seorang warga bertanya, "Bapa nanti nyapres ya pak tahun 2019, insya Allah rakyat indonesia dukung bapa khususnya anak muda :) (I'm Ladies PERSIB), dan RK membalas dengan "ai don ting about det". Kalimat "I don't 
think about that" sempat ramai jadi perbincangan ketika Jokowi yang saat itu masih menjadi Gubernur Jakarta diwawancarai Bloomberg TV. Jokowi ditanya apakah tertarik untuk menjadi Presiden Indonesia selanjutnya. Saat itu Jokowi menjawab dengan kalimat "I don't think about that" (Asfar, 2014). ${ }^{10}$ Setelah wawancara itu, muncul meme-meme di sosial media kalimat "ai don think about det", yang ternyata di kemudian hari Jokowi benar-benar mencalonkan diri dan terpilih menjadi Presiden Indonesia selanjutnya. Kalimat RK bisa diterjemahkan secara harfiah bahwa ia benar-benar tidak memikirkan hal itu, atau bisa juga ia menggunakan kiasan 'ala' Jokowi yang mengatakan tidak memikirkan hal itu tetapi sesungguhnya memikirkan hal tersebut dan ternyata benar-benar mencalonkan diri menjadi presiden. Theresia Jesslyn juga menanyakan hal yang sama melalui ask.fm. RK saat itu menjawab "belum kepikir dan gak mau mikirin. fokus mikirin bandung tercinta." Penulis menduga dua kalimat jawaban tersebut bentuk ketidakterusterangan RK, karena pada kesempatan lain, yaitu pada wawancara Aiman dan RK pada menit ke 08.24, sempat terjadi percakapan sebagai berikut:

Aiman : Jadi.. jadi walikota lima bulan kaget?

RK : $\quad 3 / 4$ kaget. $1 / 4$ nya banyak hal-hal baru yang ketahuannya setelah 5 bulan.

Aiman : Ternyata tidak mudah ya? Ini baru level kota ya?

RK :Iya tidak mudah karena level kota itu level teknis masalahnya

Aiman : Terlalu detail?

RK :Detail...Kalogubernurkan mengkoordinir kebijakan... policy... Jadi secara keruwetan teknis saya kira walikota bupati punya problem sangat kompleks.... Tapi justru itu kalo lolos problematika kota kabupaten berarti punya pengalaman yg sangat teknis sehingga kalo suatu saat jadi strategis atau generalis punya pengalaman yang matang di level teknis.

Aiman : Ini kalo di twitter hashtag-nya "kode" kalo sudah berhasil di tingkat yang lebih kecil bisa naik ke tingkat yang lebih atas hahahaha?

10 Prabowo vs Jokowi, Inilah Versi Lengkap Pernyataan I don't Think about that Jokowi. http://www. solopos. com/2014/06/04/ prabowo-vs-jokowi-inilah-versi-lengkappernyataan-i-dont-think-about-that-jokowi-511322, diakses 28 Februari 2018.
RK : Jadi kayak gini...

Aiman : Jawab dulu dong iya nggak ..hahaha?

RK : Kumaha alloh wae lah eta mah..

(bagaimana tuhan saja) nanti kita bicarakan diwaktu yang tepat.

Berdasarkan kalimat percakapan yang disampaikan RK dan bahasa tubuh yang tertawa, menyeka hidung, membetulkan tangan baju sambil mengatakan "Kumaha alloh wae lah eta mah.. nanti kita bicarakan diwaktu yang tepat", menunjukkan bahwa RK sesungguhnya sangat menyadari bahwa dirinya telah masuk dalam radar calon pemimpin potensial untuk pemilu 2019 dan dirinya sudah masuk dalam kandidat calon presiden yang potensial pada tahun 2019 . RK memberikan komentar secara cepat pada pertanyaan-pertanyaan seputar kinerjanya, akan tetapi jika ditanyakan hal- hal yang strategis seperti pencalonan capres ia menjawab dengan hati-hati. Berdasarkan analisa ini penulis memberikan penilaian yang agak rendah untuk faktor straightforwardness.

Menganalisa facet modesty pada RK agak sulit karena sebagai seorang tokoh dan pemimpin daerah tentunya ada tuntutan publik agar ia bertingkah laku ramah. Mengingat RK mempunyai karakter achievement striving yang tinggi sehingga memungkinkan perilaku ramah yang ditampilkan lebih karena achievement striving-nya. Penulis berusaha mewawancarai beberapa orang yang pernah terlibat langsung dengan RK, ternyata ada kesamaan informasi dari keduanya, bahwa RK bukan tipe orang yang mudah tersenyum dan menegur orang lain, meskipun orang itu adalah anak buahnya. Dengan lingkungan sosial masyarakat Sunda yang kuat dengan budaya kelompok perilaku seperti itu dapat diartikan sombong. Mengenai hal ini ada kemungkinan latar belakangnya yang pengusaha, profesional, pernah lama tinggal di negara dengan budaya individual berkontribusi pada gayanya yang tidak terlalu Sunda. Misalkan dalam hal bersalaman, menurut narasumber, RK selalu bersalaman dengan 1 tangan, tidak seperti kebiasaan masyarakat Sunda yang menggunakan dua tangan dan sedikit membungkukkan badan. Berdasarkan uraian diatas penulis memberikan penilaian yang rendah untuk faktor agreeableness. 
Neuroticism: Rendah pada Kesemua Facet (Skor 3)

Dari keenam facet pada neuroticism yaitu anxiety, self-consciousness, depression, vulnerability, dan impulsiveness, RK menunjukkan indikasi impulsif (impulsiveness), yaitu berperilaku dengan menuruti kata hati yang terlihat dari perilakunya, dan kecenderungannya menyukai sensasi.

Fakta ini terlihat dari bahasa tubuh yang digunakan saat wawancara acara hitam putih, dimana dia ditanyakan bagaimana cara dia leyehleyeh terhadap ibunya, kemudian tanpa canggung ia meletakkan kepalanya diatas paha ibunya dan tiduran selama beberapa saat. Pada lain kesempatan di acara Ini Talk Show Net TV, seperti telah ditulis diatas, ia duduk di sofa acara talkshow dengan cara menggelosor dari arah belakang sofa. Kemudian pada acara itu juga ia banyak memberikan respon atas ucapan pembawa acara dengan cepat dan dengan melucu. Dari uraian diatas penulis memberikan penilaian bahwa RK tidak neurotik. Ia nyaman dengan dirinya, tidak mudah cemas, bukan pemalu, tidak mudah merasa depresi, tidak rentan untuk merasa sedih atau stres.

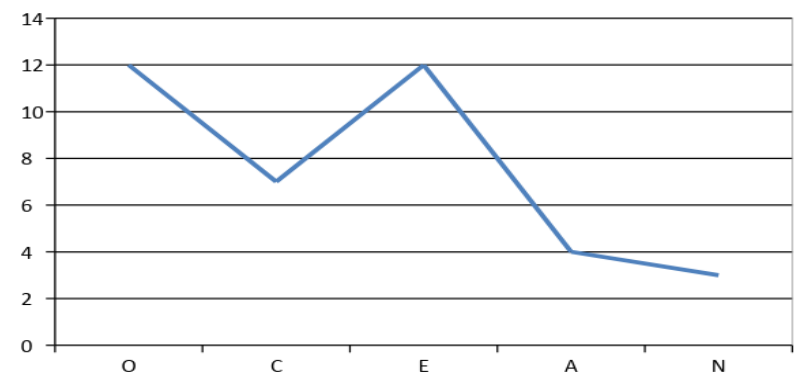

\section{Gambar 1. Grafik Skor Kepribadian Ridwan Kamil menggunakan Alat Ukur Big Five} Gambaran Profil Ridwan Kamil

Bentangan riwayat kehidupan yang telah dijalani oleh RK telah membantunya membentuk konsep yang positif akan dirinya. Ia telah memahami kekuatan dan kelemahan yang ada pada dirinya dengan baik, dan itu sangat membantu nya dalam membuat keputusan-keputusan penting dalam hidupnya. Ia mengeksplor kekuatannya secara optimal sehingga tidak heran jika pada bidangnya ia menjadi sangat menonjol.

Prestasi RK dalam bidang akademik merupakan sebuah keniscayaan. Sebagai anak yang lahir dari orang tua akademisi, dimana kedua orang tua dosen, sehingga tidak heran jika keluarga orang tua RK memberikan nilai yang tinggi akan pendidikan. Semua kakak dan adikadik mengikuti pendidikan tinggi. Oleh karena itu, pilihan RK untuk S-1 di ITB dan S-2 di Amerika Serikat (AS) merupakan suatu hal yang biasa, yang linier dengan nilai keluarganya. Akan tetapi, satu hal yang berperan penting pada garis hidup RK adalah fakta bahwa ia adalah anak kedua dan tengah di keluarganya. Menurut Adler, anak kedua dan tengah mempunyai karakteristik kompetitif, ingin mengalahkan kakaknya, memberontak, merasa tidak diperlakukan dengan adil, sehingga ia menjadi sensitif terhadap rasa ketidak adilan.

Karakteristik ini yang kemudian membuat RK selalu mendorong dirinya selalu berusaha melebihi ambang batas dirinya, ia tidak menyukai status quo, ia tidak nyaman dengan status quo, ia selalu ingin mendobrak status quo. Status quo disini bisa diartikan dengan kondisi ambang batas rata-rata, atau bisa juga diartikan kondisi yang stagnan tanpa gejolak untuk maju. Hal ini ditunjukkan dari pilihannya untuk bekerja di AS, pindah bekerja ke Hong Kong, kuliah S-2 di AS, kembali ke Indonesia setelah cukup mapan di AS, membangun perusahaannya, desain-desain arsitekturnya yang unik, bahkan pilihannya masuk ke dunia politik.

Dengan karakteristik pribadi sebagai seorang yang terbuka dengan wawasan baru, daya imajinasi tinggi, rasa seni yang kuat, dan banyak mempunyai ide-ide sangat mendukung kinerja RK sebagai walikota. Akan tetapi terdapat tuntutan peran yang agak berbeda ketika ia menjadi gubernur karena lebih banyak pada kebijakan.

Karakteristik terbuka (openness to experience) RK menjadi lebih baik karena ditambah dengan kemampuannya berpikir secara kompleks, yaitu mampu melihat berbagai sisi dari suatu persoalan. Hal ini membuat dia dapat membuat keputusan-keputusan yang baik dan aman bagi dirinya, sehingga mendukung kinerjanya.

Berdasarkan uraian atas analisa terhadap 
RK maka kata yang menurut penulis tepat untuk menggambarkan Ridwan Kamil adalah sang pendobrak status quo.

\section{DAFTAR PUSTAKA}

\section{Jurnal}

Dille, B., \& Young, M. D. (2000). The Conceptual Complexity of Presidents Carter and Clinton: an Automated Content Analysis of Temporal Stability and Source Bias. Political Psychology, 21(3), 587-596.

Hermann, M. G. (1984). Personality and Foreign Policy Decision Making: A study of 53 Heads of Government. Foreign Policy Decision Making: Perception, Cognition, And Artificial Intelligence, 53-80.

\section{Buku}

Kamil, R. \& Abdurrahim, S. (2014). \#Tetot: Aku, Kamu dan Media Sosial. Bandung: Sygma Creative Media Corp.

Kamil, R., AmaLee, I., Rahman, G.A., \& Shafiyah, Z. (2015). Mengubah Dunia Bareng-Bareng. Bandung: Kaifa.

McCrae, R.R. \& Costa Jr, P.T. (2003). Personality in Adulthood: A Five-Factor Theory Perspective. 2nd edition. New York: The Guilford Press.

Winter, D. G. (1992). Content Analysis of Archival Materials, Personal Documents, and Everyday Verbal Productions. In C. P. Smith, J. W. Atkinson, D. C. McClelland, \& J. Veroff (Eds.), Motivation and personality: Handbook of thematic content analysis (pp. 110-125). New York, NY, US: Cambridge University Press.

\section{Hasil Wawancara}

Noer, A.H. (2015). Wawancara tentang Ridwan Kamil, melalui sambungan telpon.

\section{Internet}

Asfar, A.M. (2014). Inilah Versi Lengkap Pernyataan "I Don't Think About That" Jokowi, http://www. solopos.com/2014/06/04/prabowo-vs-jokowiinilah-versi-lengkap-pernyataan-i-dont-thinkabout-that-jokowi-511322, diakses 28 Februari 2018.
Gumilar, I. (2014). Hore, Taman Alun-alun Bandung sudah Diresmikan, http://news.metrotvnews. com/read/2014/12/31/339017/hore-taman-alunalun-bandung-sudah-diresmikan, diakses 2 Maret 2018.

Herlambang, R. (2009). Ridwan Kamil: Negosiasi Kehidupan, http://rus tikaherlambang. com/2009/04/29/ridwan-kamil, diakses 27 Februari 2018.

Otto, B. \& Ismar, A. (2013). In Indonesia, a New Breed of Politician Is on the Rise, http://www. wsj.com/ articles /SB100014240527023034420 04579123080039432594 , diakses 1 Maret 2018.

Prabowo, D. (2014). Pilkada Langsung Lahirkan Pemimpin yang "Out of The Box", http://nasional. kompas. com/read/2014/09/11/18441011/ Pilkada.Langsung. Lahirkan.Pemimpin.yang. Out.of.The.Box, diakses 26 Februari 2018.

Pramantie, C. (2014). Ridwan Kamil: Laki-laki Penuh Imajinasi, http://www.tabloidnova.com/ Nova/Profil/Ridwan-Kamil-Laki-Laki-PenuhImajinasi-1/, diakses 27 Februari 2018.

Prasetyo, B. (2014). Istri Walikota Masih Keturunan Dalem Bandung, http://www.tribunnews.com/ regional/2013/09/24/istri-wali-kota-masihketurunan-dalem-bandung, diakses 26 Februari 2018.

Utari, M.D. (2015). Ridwan Kamil: Obsesi Evolusi Membawa Prestasi, https://attalicious.Word press.com/2010/02/15/ridwan-kamil-obsesievolusi-membawa-prestasi/, diakses 1 Maret 2018.

Wedhaswary, I.D. (2014). Ini Isi Perppu Pilkada yang Dikeluarkan Presiden SBY, http://nasional. kompas. com /read/2014/10/03/09190651/Ini. Isi.Perppu.Pilkada.yang.Dikeluarkan.Presiden. SBY, diakses 27 Februari 2018.

Wiyono, A.S. (2016). Survei Unpad: Warga Bandung Puas Terhadap Kinerja Ridwan Kamil. https://www.merdeka.com/peristiwa/ survei-unpad-warga-bandung-puasterhadap-kinerja-ridwan-kamil.html, diakses 27 Februari 2018.

\section{Video}

89939893116992b.(2014,Desember24).HitamPutih-24 Desember 2014-Spesial Ridwan Kamil, https:// www.youtube.com/ watch? $\mathrm{v}=\mathrm{kEvUzJj} 74 \mathrm{O} 4$, diakses 26 Februari 2018. 
Kompas TVNews. (2014, Februari 25). Aiman Dan... Ridwan Kamil \#IndonesiaSATU, https://www.youtube. com/watch?v=TOe6RRGFld8, diakses 26 Februari 2018.

Kompas TV.(2014). Ridwan Kamil: Tuna Asmara - SUPER Stand Up Seru, https://www. youtube.com/ watch? $\mathrm{v}=\mathrm{CBoTn} 32 \mathrm{P} 7 \mathrm{eM}$, diakses 26 Februari 2018.

Malbrough, R. (2015, January 14). [FULL] Ini Talkshow NET TV 23 November 2014 || spesial Ridwan Kamil, Eddi Brokoli, Budi Ci, https:// www.youtube. com/watch? v=NAGD0 vIO20, diakses 26 Februari 2018.

Najwa, M. (2014, Maret 13). FULL Mata Najwa Ridwan Kamil Menatap Yang Menata | Walikota Terhebat Dunia, https://www. youtube.com /watch?v=8XQ0pxY0A68, diakses 26 Februari 2018.
Official NET News. (2014, Agustus 30). Ridwan Kamil Ngamuk saat Penertiban Tempat Hiburan Bandung -IMS, https://www. youtube.com/ watch? $\mathrm{v}=$ gwmoc6iFPV8, diakses 26 Februari 2018.

PKS TV. (2014, Maret 2). Pidato Ridwan Kamil di Apel Siaga PKS Bandung, https://www. youtube. com/watch? $\mathrm{v}=\mathrm{KD} 4 \mathrm{HUHwP5os}$, diakses 26 Februari 2018.

TEDx Talks. (2012, May 23). TEDxBandung - Ridwan Kamil - Saving Cities with Urban Farming, https://www.youtube. com /watch? $=$ Gd6RqAXc-1Q, diakses 26 Februari 2018.

TEDx Talks. (2010, November 1). TEDxJakarta - Ridwan Kamil - Creativity and Design for Social Change in Citites, https://www. youtube.com/watch? $\mathrm{v}=\mathrm{hDw}$ _Tq $1 \mathrm{anKU}$, diakses 26 Februari 2018. 